\title{
Cardiovascular Acute Care
}

The cardiovascular system is quite expansive, involving numerous diagnoses, diagnostic tests, scoring systems, and treatment regimens, all of which can be challenging to recall. This chapter could not be all inclusive; thus, only selected elements have been included.

In this chapter, you will learn to

- differentiate myocardial ischemia from infarct,

- recognize and treat ST-elevated and non-ST-elevated myocardial infarctions,

- use common vasoactive agents,

- distinguish between shock states,

- differentiate between hypertensive urgency and emergency,

- identify causes of atrial fibrillation, and

- interpret arterial brachial index.

\section{MYOCARDIAL INFARCTIONS}

Five distinct types of myocardial infarctions (MI) have been delineated. Documentation of the specific type is required for appropriate billing and classification.

1. Spontaneous: due to acute coronary syndrome (ACS)

2. Non-ACS: ischemic necrosis due to supply/demand imbalance

3. Sudden cardiac death: no biomarkers available 
4. Procedural related:

a. Related to percutaneous intervention (PCI)

b. Related to stent thrombus

5. Coronary artery bypass graft (CABG)-related

\section{Non-ST-Elevated Myocardial Infarction (NSTEMI)}

NSTEMIs have a variety of causes that induce myocardial ischemia, including coronary reasons, noncoronary injury, and increased oxygen demands. Coronary reasons include stable plaque, vasospasm, coronary embolism, and coronary arteritis. Noncoronary causes of NSTEMI include cardiac contusion, myocarditis, and cardiotoxins. Lastly, increased oxygen demands that can lead to NSTEMI include hypotension and all shock states, hypertension, tachycardia, aortic stenosis, and pulmonary embolism. EKG findings that suggest NSTEMI include transient ST elevation, ST depression, and/or new T-wave inversions in more than one lead. Cardiac troponin elevations are noted after 4 hours. Obtain echocardiogram to identify any wall-motion abnormalities, and obtain cardiology consultation.

\section{ST-Elevated Myocardial Infarctions}

ST-elevated myocardial infarction (STEMI) is a type $1 \mathrm{MI}$ and is the result of plaque rupture with clot formation in a coronary vessel (see Figures 8.1 and 8.2). The definition of STEMI includes ST segment elevation in two or more contiguous leads $\geq 2 \mathrm{~mm}$ in leads $\mathrm{V} 2$ to $\mathrm{V} 3$, or $\geq 1 \mathrm{~mm}$ in the other chest leads or limb leads. Activate the STEMI alert within the institution immediately. Obtain echocardiogram to assess cardiac performance, and identify any wall motion or valvular abnormalities (see Table 8.1).

\section{Fast Facts}

STEMI definition includes ST segment be elevated in two or more contiguous leads $\geq 2 \mathrm{~mm}$ in leads $\mathrm{V} 2$ to $\mathrm{V} 3$, or $\geq 1 \mathrm{~mm}$ in the other chest leads or limb leads.

\section{STEMI Treatment}

STEMI treatment follows a specific algorithm. Be sure to activate the STEMI alert for your facility to mobilize appropriate resources. For PCIcapable hospitals:

1. Administer aspirin, $325 \mathrm{mg}$, chewed (buccal absorption).

2. Clopidogrel, $600 \mathrm{mg}$; or ticagrelor, $180 \mathrm{mg}$; or prasugrel, $60 \mathrm{mg}$ orally $\times 1$.

3. Heparin, 60 units/kg (maximum 5,000 units), IV bolus.

4. Transfer to cardiac cath lab for primary PCI. 


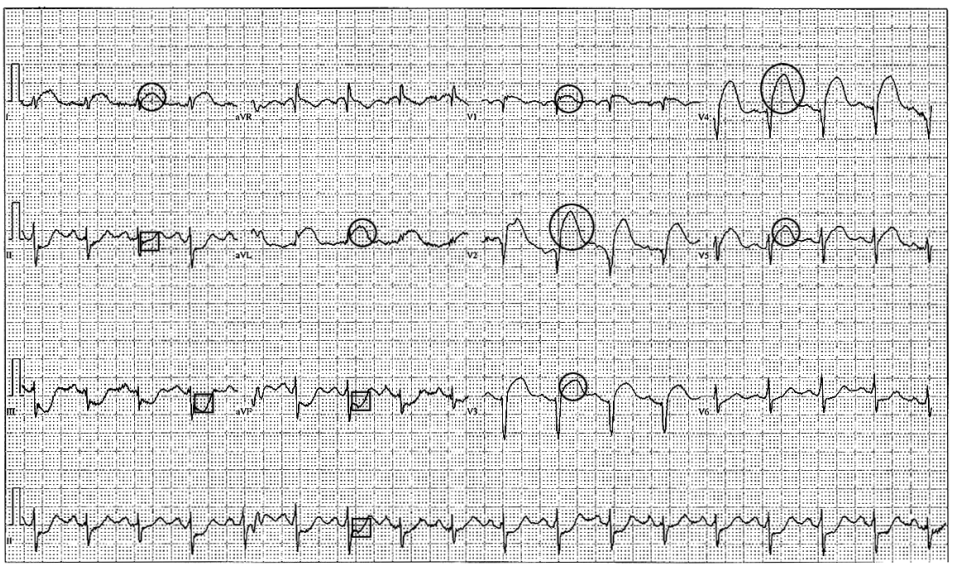

Figure 8.1 ST elevation versus depression.

Key: Box is ST depression; circle is ST elevation.

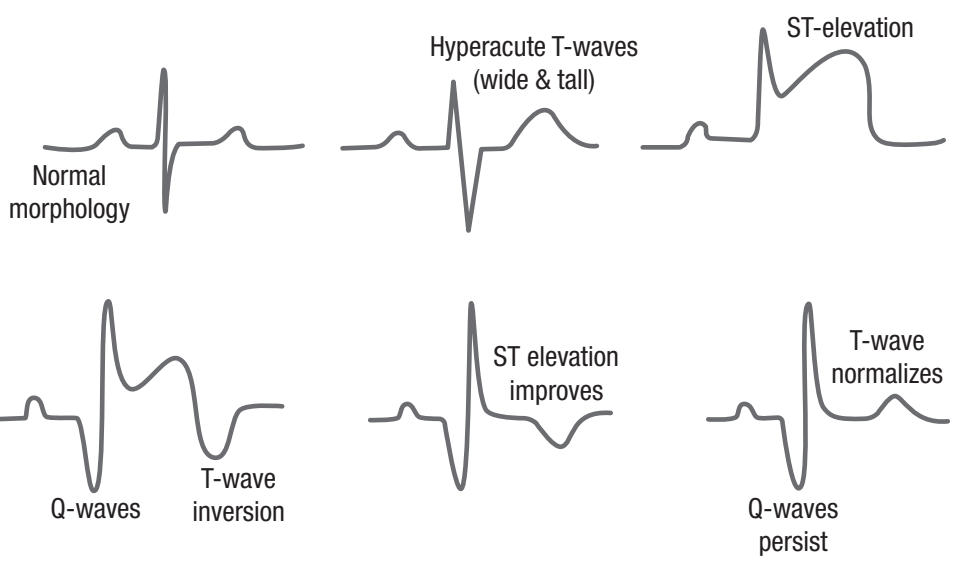

Figure 8.2 T-wave progression in STEMI.

For non-PCI-capable hospitals, transfer to PCI facility. If time to PCI will be $>120$ minutes from first medical contact, consider administration of fibrinolytics:

1. Assess for contraindications to fibrinolytics

a. Absolute contraindications

i. Prior intracranial hemorrhage

ii. Structural cerebral vascular lesions 
Table 8.1

12 Lead ECG Leads, Correlating Cardiac Region and Primary Vessel

\begin{tabular}{llll}
\hline I & & V1 & V4 \\
Lateral & aVR & Septal & Anterior \\
Cx or Diagonal & & LAD & LAD \\
II & aVL & V2 & V5 \\
Inferior & Lateral & Septal & Lateral \\
RCA & Cx or Diagonal & LAD & Cx or Diagonal \\
III & aVF & V3 & V6 \\
Inferior & Inferior & Anterior & Lateral \\
RCA $>\mathrm{Cx}$ & RCA & LAD & Cx or Diagonal \\
\hline
\end{tabular}

$\mathrm{Cx}$, circumflex; RCA, right coronary artery; LAD, left anterior descending artery.

iii. Malignant intracranial neoplasm

iv. Ischemic stroke in last 90 days

v. Suspected aortic dissection

vi. Active bleeding

vii. Significant traumatic brain injury in last 90 days

viii. Intracranial or intraspinal surgery within 60 days

ix. Severe uncontrolled hypertension that is unresponsive to therapy

b. Relative contraindications

i. Significant hypertension (SBP $>180$ or DBP $>110)$

ii. Ischemic stroke $>3$ months

iii. Dementia

iv. $\quad \mathrm{CPR}>10$ minutes

v. Major surgery within 3 weeks

vi. Recent internal bleeding within 2 to 4 weeks

vii. Vascular puncture in noncompressible vessel

viii. Pregnancy

ix. Active gastric or peptic ulcer

x. Oral anticoagulant therapy

2. Administer one of the following:

a. Tenecteplase

i. Patients $<60 \mathrm{~kg}$, administer $30 \mathrm{mg} \times 1$.

ii. Patients 60 to $69 \mathrm{~kg}$, administer $35 \mathrm{mg} \times 1$.

iii. Patients 70 to $79 \mathrm{~kg}$, administer $40 \mathrm{mg} \times 1$.

iv. Patients 80 to $89 \mathrm{~kg}$, administer $45 \mathrm{mg} \times 1$.

v. Patients $>90 \mathrm{~kg}$, administer $50 \mathrm{mg} \times 1$. 
b. Reteplase, 10 units IV $\times 2$

c. Alteplase, $15 \mathrm{mg} \mathrm{IV} \times 1$, then administer accelerated infusion:

i. For patients $<67 \mathrm{~kg}$, administer $.75 \mathrm{mg} / \mathrm{kg} /$ dose over 30 minutes, then $.5 \mathrm{mg} / \mathrm{kg} /$ dose IV over 60 minutes; maximum $100 \mathrm{mg} /$ total dose.

ii. For patients $>67 \mathrm{~kg}$, administer $50 \mathrm{mg}$ over 30 minutes, then $35 \mathrm{mg}$ IV over 60 minutes; maximum $100 \mathrm{mg} /$ total dose.

d. Then follow the previously mentioned STEMI algorithm and arrange transport to PCI facility.

\section{CLINICAL SCORES FOR ACUTE CORONARY SYNDROME (ACS)}

A variety of predictor scores have been developed to aid clinicians in the workup of ACS and prioritization of interventions. Use these tools with caution and in conjunction with clinical judgment. Commonly used tools include the TIMI (thrombolysis in Myocardial Infarction) risk score (Table 8.2), HEART (History, ECG, Age, Risk Factors, and Troponin) score (Table 8.3), GRACE (Global Registry of Acute Coronary Events) risk score, HEARTS3 score, and the Hess prediction rule. The HEART score was created specifically for use with emergency department patients.

Table 8.2

TIMI Score and 14-Day Event Rate

\begin{tabular}{llll} 
Risk factor & Points & TIMI score & 14-day event rate (\%) \\
\hline Age $65-74 / \geq 75$ & $2 / 3$ & $0-1$ & 4.7 \\
SBP $<100$ & 3 & 2 & 8.3 \\
HR $>100$ & 2 & 3 & 13.2 \\
Killip class II to IV & 2 & 4 & 19.9 \\
Anterior STE or LBBB & 1 & 5 & 26.2 \\
Diabetes, h/o HTN, or h/o & 1 & $6-7$ & 40.9 \\
angina & & & \\
Weight $<67$ kg & 1 & & \\
Time to treatment $>4$ hours & 1 &
\end{tabular}

Scores ranging from 0 to 2 constitute a low risk. Scores of 3-5 are considered intermediate risk. A score of 6 or 7 indicates high risk. 
Table 8.3

\section{The HEART Score for Chest Pain Patients in the ED}

\begin{tabular}{lll}
\hline History & - Highly suspicious & -2 points \\
& - Moderately suspicious & -1 point \\
& - Slightly suspicious or & -0 points \\
& nonspecific & \\
& - Significant ST depression & -2 points \\
EKG & - Nonspecific repolarization & -1 point \\
& - Normal & -0 points \\
Age & -65 years old & -2 points \\
& $-45-65$ years old & -1 point \\
& $-\leq 45$ years old & -0 points \\
Risk factors: HTN, HLD, DM, & $->3$ factors or FHx of CAD & -2 points \\
obesity, current/recent smoker & -1 or 2 risk factors & -1 point \\
$(<1$ mo) or FHx of CAD & -0 risk factors & -0 points \\
Troponin & $-3 \times$ normal limit & -2 points \\
& -1 to $<3 \times$ normal limit & -1 point \\
& $-\leq$ normal limit & -0 points
\end{tabular}

Interpretation: Occurrence of major adverse cardiac events (MACE) at 6 weeks MACE $=$ AMI, PCI, CABG, and death:

- Score $0-3=2.5 \%$ MACE over next 6 weeks - discharge home

- Score 4-6 $=30.3 \%$ MACE over next 6 weeks - admit for observation

- Score 7-10 = 72.7\% MACE over next 6 weeks - early invasive strategies

AMI, acute myocardial infarction; $C A B G$, coronary artery bypass grafting; $C A D$, coronary artery disease; DM, diabetes mellitus; $\mathrm{ED}$, emergency department; FHx, family history; HLD, hypercholesterolemia; HTN, hypertension; MACE, major adverse cardiac event; PCI, percutaneous coronary intervention.

\section{Thrombolysis in Myocardial Infarction (TIMI) Score}

The TIMI score is used to determine the likelihood of ischemic events or mortality in patients with unstable angina or NSTEMI.

\section{Killip Classification}

The Killip classification is used with patients who have acute STEMIs to predict inpatient mortality (Table 8.4 ). The higher the Killip classification, the higher the risk of in-hospital mortality.

\section{HEART FAILURE}

A significant sequela of MIs is heart failure, although not all heart failure is caused by MIs or ischemia. AG-ACNPs frequently diagnose and manage heart failure. Ensuring accuracy of terminology, differentiating between left and right heart failure, and identifying the functional classification of heart failure are fundamental skills for AG-ACNPs to possess (see Tables 8.5 to 8.8 ). 
Killip Classification and Mortality

\begin{tabular}{lll} 
Class & Description & Mortality (\%) \\
\hline I & No evidence of CHF & 1.5 \\
II & Rales, increased JVD, S3 & 3.7 \\
III & Pulmonary edema & 16.7 \\
IV & Cardiogenic shock & 36.7
\end{tabular}

CHF, congestive heart failure; JVD, jugular venous distention.

Table 8.5

HFpEF vs. HFrEF Comparison

\begin{tabular}{cll} 
Classification & Ejection fraction & Description \\
\hline I. HFrEF & $\leq 40 \%$ & Also referred to as systolic heart failure. \\
II. HFpEF & $\geq 50 \%$ & Also referred to as diastolic heart failure. \\
a. HFmEF & $41-49 \%$ & $\begin{array}{l}\text { HFmEF = heart failure with mid-range ejection } \\
\text { fraction. Treatment patterns similar to HFpEF. }\end{array}$ \\
$\begin{array}{l}\text { b. HFpEF, } \\
\text { improved }\end{array}$ & $>40 \%$ & $\begin{array}{l}\text { Subset of patients with HFpEF previously had } \\
\text { HFrEF. Recovery may be clinically different } \\
\text { from those with persistently reduced EF. }\end{array}$ \\
\hline
\end{tabular}

HFmEF, heart failure mid-range ejection fraction; HFpEF, heart failure with preserved ejection fraction; HFrEF, heart failure with reduced ejection fraction.

Table 8.6

\section{Exam Findings of Right- vs. Left-Sided Heart Failure}

\begin{tabular}{ll} 
Right & Left \\
\hline Clinical and Exam Findings: & Clinical and Exam Findings: \\
- CVP $>15$ & - PCWP $>15$ \\
- Juglar venous distention & - Shortness of breath \\
- Hepatic jugular reflex & - Increased work of breathing \\
- Peripheral edema & - Crackles in lung fields \\
- Pants or shoes fitting tighter & - Cephalization on CXR \\
\hline
\end{tabular}

CVP, central venous pressure; CXR, chest $\mathrm{x}$-ray; PCWP, pulmonary capillary wedge pressure.

\section{SHOCK STATES}

Diagnosing and managing shock is central to the AG-ACNP role. Patients who are older, medically frail, and immunocompromised do not always present with classic signs and symptoms, thus diagnosing shock can prove challenging. Additionally, a patient can experience two 
Table 8.7

New York Heart Association Functional Classification and Symptom Descriptor

\begin{tabular}{lll} 
Class & Definition & Other descriptor \\
\hline I & No symptoms & Asymptomatic \\
II & Symptoms with ordinary activity & Mild symptoms \\
III & Symptoms with less-than-ordinary activity & Moderate symptoms \\
IV & Symptoms at rest or with any minimal activity & Severe symptoms \\
\hline
\end{tabular}

Table 8.8

\section{ACC/AHA Heart Failure Stages}

\begin{tabular}{ll} 
Stage & Description \\
\hline A & $\begin{array}{l}\text { Patient is at high risk for developing HF in the future but no functional or } \\
\text { structural heart disorder. }\end{array}$ \\
B & A structural heart disorder but no symptoms. \\
C & $\begin{array}{l}\text { Previous or current symptoms of heart failure in the context of an under- } \\
\text { lying structural heart problem, managed with medical treatment. }\end{array}$ \\
D & $\begin{array}{l}\text { Advanced disease requiring hospital-based support, a heart transplant, or } \\
\text { palliative care. }\end{array}$
\end{tabular}

ACC, American College of Cardiology; AHA, American Heart Association.

or more types of shock simultaneously. Thus the AG-ACNP must constantly consider and assess for each type of shock (see Table 8.9).

\section{Causes of Hypotension:}

C-Cardiac-check EKG and troponin.

$\mathrm{H}-$ Hypovolemia-assess fluid status and responsiveness, perform passive leg raise.

A-Anaphylaxis-check recent medications.

S-Sepsis-check lactate.

E-Endocrine-adrenal insufficiency -check random cortisol level.

\section{Shock Index and Modified Shock Index:}

Shock index (SI) is defined as the heart rate (HR) divided by systolic blood pressure (SBP) (HR/SBP). Example: HR 110, BP 80/60, SI = 110/80 = 1.375. Normal range is .5 to .7 in healthy adults. A SI $>1.1$ predicts increased risk for morbidity and mortality, including patients who may need massive transfusion protocol (MTP) activation and/or admission to critical 
Hemodynamics by Type of Shock

\begin{tabular}{llccc} 
Type of shock & $\begin{array}{l}\text { CVP/PCWP } \\
\text { preload }\end{array}$ & CO & SVR afterload & SV02 \\
\hline Hypovolemic & $\downarrow$ & $\downarrow$ & $\uparrow$ & $\downarrow$ \\
Cardiogenic & $\uparrow$ & $\downarrow$ & $\uparrow$ & $\downarrow$ \\
Distributive-septic & $\downarrow$ & $\uparrow$ & $\downarrow$ & $\uparrow$ \\
Distributive-neurogenic & $\downarrow$ & $\downarrow$ & $\downarrow$ & $\downarrow$ \\
Distributive-anaphylactic & $\downarrow$ & $\downarrow$ & $\downarrow$ & $\leftrightarrow$ \\
Obstructive & $\uparrow$ & $\downarrow$ & $\leftrightarrow$ & $\leftrightarrow$ \\
Adrenal insufficiency & $\leftrightarrow$ & $\downarrow$ & $\leftrightarrow$ & $\downarrow$ \\
\hline
\end{tabular}

CO, cardiac output; CVP, central venous pressure; PCWP, Pulmonary capillary wedge pressure; SVR, systemic vascular resistance.

Table 8.10

\section{Classification of Hemorrhagic Shock}

\begin{tabular}{lllll} 
& Class I & Class II & Class III & Class IV \\
\hline Blood loss & 750 & $750-1,500$ & $1,500-2,000$ & $>2,000$ \\
\% blood volume & $15 \%$ & $15-30 \%$ & $30-40 \%$ & $>40 \%$ \\
HR & $<100$ & $>100$ & $>120$ & $>140$ \\
BP & Normal & Normal & Decreased & Decreased \\
Cap refill & Normal & Decreased & Decreased & Decreased \\
RR & $14-20$ & $20-30$ & $30-40$ & $>35$ \\
U/O & $>30 \mathrm{~mL} / \mathrm{hr}$ & $20-30 \mathrm{~mL} / \mathrm{hr}$ & $5-15 \mathrm{~mL} / \mathrm{hr}$ & Negligible \\
Mental status & Slightly & Anxious & Anxious/ & Confused/ \\
& anxious & & confused & lethargic \\
Fluid replacement & Crystalloid & Crystalloid/Blood & Blood & Blood \\
\hline
\end{tabular}

care units. Alternatively, the modified shock index (MSI) is defined as HR divided by mean blood pressure (MAP), (HR/MAP). Example: HR 110 , MAP $50=$ MSI $=2.2$. An MSI of $>1.4$ is a predictor of higher morbidity and mortality. The MSI is a stronger predictor of mortality than SI for emergency room patients, as HR and SBP may be influenced by other factors, including pain, agitation, and so forth.

Hemorrhagic shock can be quantified by VS that correlate with amount of hemorrhage (see Table 8.10). Vasoactive agents are commonly required to manage the various types of shock. See Table 8.11 for the variety of vasoactive infusions, dosing, receptor activity, and cardiovascular effects. 
Vasoactive infusions, Dosing, Receptor Activity, and Cardiovascular Effects

Drug and Doses

Inopressors

Dopamine (Inotropin)

$.5-5 \mathrm{mcg} / \mathrm{kg} / \mathrm{min}$

$5-10 \mathrm{mcg} / \mathrm{kg} / \mathrm{min}$

$10-20 \mathrm{mcg} / \mathrm{kg} / \mathrm{min}$

Epinephrine

$.01-.05 \mathrm{mcg} / \mathrm{kg} / \mathrm{min}$

$>.05 \mathrm{mcg} / \mathrm{kg} / \mathrm{min}$

Norepinephrine (Levophed)

.5-30 $\mathrm{mcg} / \mathrm{min}$ or

$.01-.04 \mathrm{mcg} / \mathrm{kg} / \mathrm{min}$

Pure vasopressors

Angiotensin II (Giapreza)

.125-40 ng/kg/min

Phenylephrine

(Neosynephrine)

$2-300 \mathrm{mcg} / \mathrm{min}$ or

.1-1 $\mathrm{mcg} / \mathrm{kg} / \mathrm{min}$

Vasopressin (Pitressin)

$.01-.06$ units/min

Inodilators

Dobutamine (Dobutrex)

$2-10 \mathrm{mcg} / \mathrm{kg} / \mathrm{min}$

$10-20 \mathrm{mcg} / \mathrm{kg} / \mathrm{min}$

Milrinone (Primacor)

$.375-.75 \mathrm{mcg} / \mathrm{kg} / \mathrm{min}$

Isoproterenol (Isuprel)

$2-10 \mathrm{mcg} / \mathrm{min}$

Vasodilators

Nitroglycerine

$1-50 \mathrm{mcg} / \mathrm{min}$

$>50 \mathrm{mcg} / \mathrm{min}$

Nitroprusside (Nipride)

10-200 $\mathrm{mcg} / \mathrm{min}$

.2-4 $\mathrm{mcg} / \mathrm{kg} / \mathrm{min}$

\section{Mechanism of action Main effects}

Angiotensin II $\quad \mathrm{VC}+++$

$a++++$

$\mathrm{VC}++++, \mathrm{HR} \varnothing /-$

$$
\begin{aligned}
& \alpha+, \beta-1++++ \\
& \text { cAMP } \\
& \beta-1++++
\end{aligned}
$$

Increases cGMP production

Increases cGMP production

$\mathrm{CH}$, chronotropy; $\mathrm{CO}$, cardiac output; $\mathrm{HR}$, heart rate; I, inotropy; MAP, mean arterial blood pressure; $\varnothing$, no change; $\mathrm{VC}$, vasoconstriction; $\mathrm{VD}$, vasodilation; +, slight; ++, mild; +++, moderate; ++++, maximum; -, slight decrease; $v$, variable effects dependent on clinical status. 
Patients who experience shock are at high risk for complications. Common complications include ischemia, organ failure, and complications of treatments. Ischemic complications include myocardial ischemia, which may be STEMI or NSTEMIs, ischemic stroke, gastrointestinal ischemia, or deep vein thrombosis. Organ failure includes acute kidney injury/acute renal failure, acute respiratory distress syndrome, and acute liver failure. Sequelae of treatments and interventions include abdominal compartment syndrome, disseminated intravascular coagulation, ventilator-associated pneumonia, and other hospital-acquired infections, with or without multidrugresistant organisms, multisystem organ failure, pressure ulcers, ICUacquired weakness from critical illness myopathy or neuropathy, and post-ICU syndrome. The AG-ACNP must maintain a high index of suspicion to identify these sequelae. Additionally, the AG-ACNP should institute preventative measures and undertake ongoing assessment and monitoring for early identification and treatment of such complications.

\section{SEVERE HYPERTENSION VERSUS HYPERTENSIVE EMERGENCY}

The primary factor distinguishing between hypertensive urgency and emergency is target organ damage. Should a patient develop encephalopathy, acute kidney injury, MI, aortic dissection, and so forth, then hypertensive emergency is diagnosed. Both conditions require controlled reduction in blood pressure to prevent further injury to organs (see Table 8.12 for medication infusions and dosing). Identifying the causative factor is critical to prevent relapse. Commonly, the causative factor is decreased medication adherence, which requires further exploration. Assess for cost increases; prescription not being refilled in a timely manner; patient unable to pick up prescription from pharmacy or prescription not delivered in a timely manner; insurance changes requiring preauthorization or change to a higher-tier copay; or that the patient confused medications or could not tolerate side effects. Be sure to engage social work and case management along with primary care provider (PCP) to identify costeffective treatment options prior to discharge.

\section{Fast Facts}

Hypertensive emergency should have blood pressure reductions of no greater than $25 \%$ in the first 24 hours to prevent hypoperfusion of vital organs, which could cause further target organ damage. 
Table 8.12

\section{Antihypertensive Infusions and/or Bolus Dosing}

\begin{tabular}{|c|c|c|}
\hline Drug & MOA & Dosing \\
\hline $\begin{array}{l}\text { Diltiazem } \\
\text { (Cardizem) }\end{array}$ & $\begin{array}{l}\text { Non-dihydropyridine } \\
\text { calcium channel blocker }\end{array}$ & $\begin{array}{l}\text { Initial bolus } 2.5-10 \mathrm{mg} \text { followed by an } \\
\text { infusion } 2.5-15 \mathrm{mg} / \mathrm{hr}\end{array}$ \\
\hline $\begin{array}{l}\text { Esmolol } \\
\text { (Breviblock) }\end{array}$ & Selective beta- 1 blocker & $\begin{array}{l}\text { Initial bolus of } 50 \mathrm{mcg} \text {, followed by an } \\
\text { infusion } 50-300 \mathrm{mcg} / \mathrm{kg} / \mathrm{min}\end{array}$ \\
\hline $\begin{array}{l}\text { Labetalol } \\
\text { (Trandate) }\end{array}$ & $\begin{array}{l}\text { Selective alpha- } 1 \text { and } \\
\text { nonselective beta- } 1 \text { and } \\
\text { beta- } 2 \text { blocker }\end{array}$ & $\begin{array}{l}20-80 \mathrm{mg} \text { IV Q } 10-30 \mathrm{~min} \text {, } \\
\text { or } 1-2 \mathrm{mg} / \mathrm{min} \text { IV infusion }\end{array}$ \\
\hline $\begin{array}{l}\text { Nicardipine } \\
\text { (Cardene) }\end{array}$ & $\begin{array}{l}\text { Dihydropyridine calcium } \\
\text { channel blocker }\end{array}$ & $\begin{array}{l}\text { Infusion: } 5 \mathrm{mg} / \mathrm{hr} \mathrm{IV} \text {, may increase by } \\
2.5 \mathrm{mg} / \mathrm{hr} \text { Q } 5-15 \mathrm{~min} \text { to } \max \text { of } 15 \mathrm{mg} / \mathrm{hr}\end{array}$ \\
\hline $\begin{array}{l}\text { Enalapril } \\
\text { (Vasotec) }\end{array}$ & $\begin{array}{l}\text { Angiotensin-converting } \\
\text { enzyme inhibitor }\end{array}$ & $\begin{array}{l}1.25 \mathrm{mg} \text { IV Q } 6 \mathrm{hr} \text {; } \max 20 \mathrm{mg} / 24 \mathrm{hr} \text {; avoid } \\
\text { or reduce dose in acute kidney injury } \\
{ }_{* \star} \text { Fetal/neonatal morbidity/mortality, d/c } \\
\text { drug ASAP when pregnancy detected. }\end{array}$ \\
\hline $\begin{array}{l}\text { Nitroprusside } \\
\text { (Nipride) }\end{array}$ & Vasodilator/nitrate & $\begin{array}{l}3-4 \mathrm{mcg} / \mathrm{kg} / \mathrm{min} \text { IN infusion; increase by } \\
.5 \mathrm{mcg} / \mathrm{kg} / \mathrm{min} \text { Q } 5 \mathrm{~min} \max 10 \mathrm{mcg} / \mathrm{kg} / \\
\mathrm{min} \\
{ }^{* *} \text { Cyanide and thiocyanate metabolites } \\
\text { can be toxic at higher levels. }\end{array}$ \\
\hline
\end{tabular}

\section{ATRIAL FIBRILLATION}

Atrial fibrillation (AF) is a common problem for AG-ACNPs to diagnose and manage. Determine whether this is an existing or new problem. New AF must be evaluated and causative factor(s) determined in order to treat appropriately. An easy mnemonic to recall causes of AF is PIRATES.

Causes of atrial fibrillation:

P-Pulmonary embolism, potassium

I-Ischemia, infection, inflammation

$\mathrm{R}$-Respiratory distress

A-Atrial enlargement $=$ volume overload

T-Thyroid disease

E-Ethanol intake

S-Sepsis, sleep apnea

\section{Fast Facts}

Identifying the cause of AF is key to effective treatment. 


\section{$\mathrm{CHA}_{2} \mathrm{DS}_{2}$ VASC Score}

\begin{tabular}{llll} 
Risk factor & Score & Risk factor & Score \\
\hline CHF or LVEF $\leq 40 \%$ & 1 & $\begin{array}{l}\text { Stroke/TIA/ } \\
\text { Thromboembolism }\end{array}$ \\
Hypertension & 1 & Vascular disease & 1 \\
Age $\geq 75$ & 2 & Age 65-74 & 1 \\
Diabetes & 1 & Female & 1 \\
Interpretation: CHEST 2018 & Interpretation: AHA/ACC/HRS 2019 \\
-1 for males or & & -2 for males or \\
-2 for females & & -3 for females \\
- (i.e., at least one non-sex risk factor) & - (i.e., at least two non-sex risk factors) \\
First line therapy (for both) is DOAC therapy over warfarin.
\end{tabular}

ACC, American College of Cardiology; AHA, American Heart Association; CHF, congestive heart failure; DOAC, direct oral anticoagulant; HRS, Heart Rhythm Society; LVEF, left ventricular ejection fraction; TIA, transient ischemic attack.

\section{Fast Facts}

Carotid massage is no longer an acceptable vagal maneuver for atrial fibrillation due to the high risk of carotid artery plaque rupture, causing embolic ischemic strokes.

The decision to anticoagulate hospitalized patients with AF is complicated, and many factors should be considered, including the cause of $\mathrm{AF}$, the duration of $\mathrm{AF}$, and a comparison of the risks of stroke versus bleeding. Comparing the results of the $\mathrm{CHA}_{2} \mathrm{DS}_{2}$ VASC score and the HAS-BLED scores to see which is greater will aid discussions with the patient and their family (see Tables 8.13 and 8.14).

\section{VASCULAR DISORDERS}

\section{Aneurysms}

Three types of aortic aneurysms exist, including ascending thoracic, descending thoracic, and abdominal aneurysms. Thoracic aortic aneurysms are commonly asymptomatic, with many being detected incidentally during other diagnostic testing of the chest. Risk factors include hypertension, connective tissue disorders such as Marfan syndrome or Ehlers-Danlos, bicuspid aortic valve, massive blunt chest trauma, cocaine 
Table 8.14

\section{HAS-BLED Score and Interpretation}

\begin{tabular}{ll} 
Risk factor & Score \\
\hline Hypertension $(\mathrm{SBP}>160)$ & 1 \\
Abnormal renal or liver function & $1-2$ \\
Stroke & 1 \\
Bleeding tendency or predisposition & 1 \\
Labile INR & 1 \\
Age $>65$ & 1 \\
Drugs (concomitant ASA/NSAIDs) or & $1-2$ \\
alcohol & \\
Interpretation: $0-2=$ low risk of bleeding; $\geq 3$ = high risk of bleeding.
\end{tabular}

ASA, aspirin; INR, international normalized ratio; NSAIDS, nonsteroidal anti-inflammatory drug; SBP, systolic blood pressure.

abuse, and preeclampsia. Symptoms are a result of compressed anatomy as the aneurysm expands. Symptoms include shortness of breath, wheezing, dysphagia, and hoarseness. Mediastinal widening on chest X-ray and associated murmur of aortic regurgitation due to involvement of the bicuspid aortic valve are common exam findings. Indications for repair include symptomatic aneurysms and aneurysms over $5.5 \mathrm{~cm}$ in diameter for the general population, and $5.0 \mathrm{~cm}$ in those with bicuspid aortic valve. The Stanford classification denotes two types of aneurysms. Type A aneurysms extend from the aortic root through the aortic arch, and type $\mathrm{B}$ aneurysms extend along the descending aorta.

Abdominal aneurysms are defined as dilatation of the aorta $\geq 3 \mathrm{~cm}$. Screening abdominal ultrasounds are recommended for all men ages 65 to 75 with any smoking history. Rupture is more common with aneurysms $\geq 5 \mathrm{~cm}$ and pose a $12 \%$ mortality for men and $18 \%$ for women, which increases dramatically as the aneurysm increases in size.

Aortic dissections commonly present with the patient complaining of sudden severe back pain or syncope. The pain is classically described as tearing or ripping in nature but more commonly as sharp or stabbing. An exam can reveal unequal pulses or pulse deficits in approximately $30 \%$ of patients. Computerized tomography angiography (CTA) scans are the gold standard for diagnosing aortic dissections.

Preoperative management and medical management for nonsurgical candidates include aggressive blood pressure management. IV labetalol prn or labetalol or esmolol infusions to achieve systolic blood pressure $<120 \mathrm{mmHg}$ and a heart rate close to 60 beats per minute. Definitive surgical intervention is essential, as every hour delay substantially increases mortality. Endovascular repair is the recommended approach for repair. 
Complications of aneurysms and their associated dissection or rupture include acute kidney injury, ischemic stroke, spinal cord ischemia, postoperative hemorrhage, and mesenteric ischemia. Mesenteric ischemia is rare but has significant mortality, and is manifested by persistent lactic acidosis or bowel movements early in the postoperative period.

\section{Fast Facts}

Preoperative goals for aortic dissections are systolic blood pressure $<120 \mathrm{mmHg}$ and a heart rate of 60 beats per minute. Aggressively titrate labetalol or esmolol infusions to urgently achieve these goals.

\section{Venous Thromboembolism}

Venous thromboembolism (VTE) and peripheral arterial disease (PAD) are common conditions AG-ACNPs will diagnose and manage. While differentiating between the pathophysiology of these two phenomena seems logical, many students and new NPs can get confused. Especially important to consider are the consequences of deep vein thrombosis (DVT) migrating and becoming a pulmonary embolus (PE) and risk factors of PAD progressing to acute limb ischemia, both of which could lead to loss of limb or life (see Table 8.15).

Every hospitalized patient should have DVT prophylaxis ordered upon admission. Both mechanical and chemoprophylaxis should be ordered unless contraindicated. If contraindications are present, they must be documented. Failure to document contraindications leads legal experts to contend it was negligence on the provider's part should an illintended consequence occur. Additionally, early mobility is critical for DVT prevention as well as for other benefits.

To determine the patient's probability of having a DVT, calculate the Wells Criteria score. For moderate or high suspicion for DVT, consider additional diagnostic testing based on the likelihood of the patient having a DVT (see Table 8.16).

\section{Diagnostic Testing}

D-dimer has about $98 \%$ sensitivity but only $50 \%$ specificity and is useful to rule out VTE/PE; however, it is not recommended for use in patients who already have their coagulation cascade triggered, such as surgical or trauma patients, or cancer or pregnant patients. Venous duplex is the best test to diagnose DVT. CT angiogram is indicated when pulmonary embolus (PE) is suspected. When patients are too unstable hemodynamically or contrast load is contraindicated, consider transthoracic echocardiogram (TTE). TTE can demonstrate right ventricular strain, or dysfunction, but is not diagnostic for PE. 
Table 8.15

\section{Comparison of DVT and PAD Risk Factors and Symptomatology}

\section{Deep vein thrombosis}

Risk factors

- Major surgery or trauma (abdominal, pelvic, hip/knee replacement)

- Cancer

- Immobility

- Pregnancy

- Obesity

- Contraceptive use or hormone replacement

- Invasive devices (PICC lines, CVC)

- Heparin-induced thrombocytopenia

- Hereditary factors (Factor V Leiden deficiency, antithrombin deficiency, protein $\mathrm{C}$ deficiency, protein $\mathrm{S}$ deficiency, antiphospholipid syndrome)

Signs and Symptoms

- Pain (mild)/tenderness

- Unilateral edema of affected leg/foot, may be bilateral edema if DVT is bilateral

- Erythema

- Warmth

- Change in color

\section{Peripheral arterial disease}

Risk factors

- Atrial fibrillation

- Hyperlipidemia

- Diabetes

- Smoking

- Medications (COX-2 inhibitors)

- Devices (mechanical valve)

- Aneurysms with distal embolization

- External compression

- History of prior trauma

- Vasculitis

- Radiation injury

Signs and Symptoms

- Claudication

- Pale

- Poor nail/hair growth

- Cooler extremity

- Thin, shiny skin

- Reduced ankle-brachial index

CVC, central venous catheter; DVT, deep vein thrombosis; PAD, peripheral arterial disease; PICC, peripherally inserted central catheter.

The primary treatment option for most patients is systemic anticoagulation. Refer to the American College of Chest Physicians (ACCP) guidelines for VTE treatment. Medication options include unfractionated heparin, low-molecular-weight heparin, and oral anticoagulants. For patients who have contraindications to systemic anticoagulation, consider a temporary inferior vena cava (IVC) filter. For patients with RV strain or hemodynamic instability, consider systemic thrombolytic therapy (alteplase $100 \mathrm{mg}$ IV over 2 hours) or catheter-directed thrombolysis. Consult interventional radiology or vascular surgery for endovascular thrombectomy. Extracorporeal membrane oxygenation (ECMO) may be required to bridge patient to an open surgical thrombectomy by a cardiothoracic surgeon. Assess whether or not your institution has a pulmonary embolism response team and how to access them, prior to an emergent situation. 


\section{Simplified Wells Criteria for DVT}

\begin{tabular}{|c|c|c|}
\hline \multicolumn{2}{|l|}{ Clinical indicator: } & Points \\
\hline \multicolumn{2}{|c|}{ Active cancer (ongoing treatment or within 6 months) } & 1 \\
\hline \multicolumn{2}{|c|}{ Paralysis or recent immobilization of lower extremity } & 1 \\
\hline \multicolumn{2}{|c|}{$\begin{array}{l}\text { Recent bed rest for } \geq 3 \text { days or major surgery within } \\
3 \text { months }\end{array}$} & 1 \\
\hline \multicolumn{2}{|c|}{ Local tenderness along deep vein system } & 1 \\
\hline \multicolumn{2}{|l|}{ Entire leg swelling } & 1 \\
\hline \multicolumn{2}{|c|}{ Calf $\geq 3 \mathrm{~cm}$ larger (at $10 \mathrm{~cm}$ below tibial tuberosity) } & 1 \\
\hline \multicolumn{2}{|c|}{ Pitting edema of affected leg } & 1 \\
\hline \multicolumn{2}{|c|}{ Collateral superficial veins (nonvaricose) } & 1 \\
\hline \multicolumn{2}{|l|}{ Previous DVT } & 1 \\
\hline \multicolumn{2}{|c|}{ Alternative diagnosis at least as likely } & -2 \\
\hline \multicolumn{3}{|l|}{ Pretest probability: } \\
\hline Score 0 & Score 1 or 2 & Score $>3$ \\
\hline Low probability (5\%) & Moderate (17\%) & High probability (53\%) \\
\hline
\end{tabular}

DVT, deep vein thrombosis.

\section{Limb Ischemia}

PAD can lead to chronic or acute limb ischemia. Modification of risk factors can stop the progression of atherosclerosis and its associated sequelae. Monitor ankle brachial indexes for progression of chronic limb ischemia. Ankle brachial indexes of .41 to .9 are typical for patients complaining of claudication. Critical limb ischemia is denoted with an ABI <.41 and requires referral to a vascular surgeon, if this has not been done previously.

\section{Ankle-Brachial Index}

The ankle-brachial index (ABI) is the systolic pressure of the posterior tibial artery divided by the highest systolic blood pressure of either brachial artery. The ABI is both a sensitive and specific metric to diagnose PAD. Segmental blood pressures in the thigh, calf, ankle, and metatarsal regions can help pinpoint the blockage. Interpretation of ABIs is noted in Table 8.17.

\section{Acute Limb Ischemia}

Acute limb ischemia is a surgical emergency, occurring when arterial blood flow is completely disrupted to an extremity. The hallmark sign 


\section{$\mathrm{ABI}$ Interpretation}

\begin{tabular}{lll} 
ABI value & Interpretation & Action \\
\hline$>1.4$ & $\begin{array}{l}\text { Calcified or hardened vessel, } \\
\text { noncompressible }\end{array}$ & Refer to vascular surgeon \\
$1.0-1.4$ & Normal & Modify risk factors \\
$.9-1.0$ & Acceptable & Modify risk factors \\
$.8-.9$ & Some arterial disease & Modify risk factors \\
$.5-.8$ & Moderate arterial disease & Refer to vascular surgeon \\
$<.5$ & Severe arterial disease & Refer to vascular surgeon \\
\hline
\end{tabular}

is abrupt onset of excruciating pain in the affected limb. Additionally, patients commonly complain of numbness or paresthesia and paralysis. Pulses are absent and the limb is cool to touch. Anticoagulation and either open or endovascular reperfusion interventions are the immediate interventions required to salvage the limb.

\section{Fast Facts}

Classic signs of acute limb ischemia include the six Ps: pain, pallor, paresthesia, paralysis, pulselessness, and poikilothermia (cool to touch).

In summary, this chapter summarizes a small fragment of required knowledge for AG-ACNPs to care for patients with cardiovascular disease. The most lethal or limb-threatening problems have been touched upon. Be sure to do in-depth reading of texts and clinical practice guidelines to support your knowledge base.

\section{References}

Aday, A. W., \& Beckman, J. A. (2017). Diseases of the Aorta. In S. C. McKean, J. J. Ross, D. D. Dressler, \& D. B. Scheurer (Eds.), Principles and Practice of Hospital Medicine (2nd ed., pp. 2107-2114). McGraw Hill Education.

Basit, H., Malik, A., \& Huecker, M. R. (2021). Non ST segment elevation myocardial infarction. StatPearls Publishing. www.ncbi.nlm.nih.gov/books/ NBK513228

Casey, S., Lanting, S., Oldmeadow, C., \& Chuter, V. (2019). The reliability of the ankle brachial index: A systematic review. Journal of Foot and Ankle Research, 12(1), 39. https://doi.org/10.1186/s13047-019-0350-1 
Kearon, C., Akl, E. A., Ornelas, J., Blaivas, A., Jimenez, D., Bounameaux, H., Huisman, M., King, C. S., Morris, T. A., Sood, N., Stevens, S. M., Vintch, J. R. E., Wells, P., Woller, S. C., \& Moores, L. (2016). Antithrombotic therapy for VTE disease: CHEST guideline and expert panel report. Chest, 149(2), 315-352. https://doi.org/10.1016/j.chest.2015.11.026

Koch, E., Lovett, S., Nghiem, T., Riggs, R. A., \& Rech, M. A. (2019). Shock index in the emergency department: Utility and limitations. Open Access Emergency Medicine, 179-199. https://doi.org/10.2147/OAEM.S178358

Lawler, P. R., \& Morrow D. A. (2017). Cardiovascular conditions in the ICU -Acute Coronary syndromes and other common cardiac problems. In G. Frendl \& R. D. Urman (Eds.), Pocket ICU (2nd ed., pp. 1-15). Wolters Kluwer. McDaniel, M. (2017). Acute coronary syndromes. In S. J. McKean, J. J. Ross, D. D. Dressler, \& D. B. Scheurer (Eds.), Principles and Practice of Hospital Medicine (2nd ed., pp. 929-940). McGraw Hill Education.

Mekkaoui, S., Pelletier-Bui, A., \& Ginty, C. (2017, 18 April 2017). Back to basics: ECG findings in acute myocardial infarction: Identifying the culprit vessel. www.emdaily.cooperhealth.org/content/back-basics-ecg-findings-acute -myocardial-infarction-identifying-culprit-vessel

Palmer, L. J. \& Berg, S. (2017). Vascular surgical critical care. In G. Frendl \& R. D. Urman (Eds.), Pocket ICU (pp. 1-4). Wolters Kluwer.

Shah, S. K., \& Belkin, M. (2017). Acute and chronic lower limb ischemia. In S. J. McKean, J. J. Ross, D. D. Dressler, \& D. B. Scheurer (Eds.), Principles and Practice of Hospital Medicine (pp. 211-212). McGraw Hill Education.

Wever-Pinzon, O. \& Fang, J. C. (2017). Heart failure. In S. J. McKean, J. J. Ross, D. D. Dressler, \& D. B. Scheurer (Eds.), Principles and Practice of Hospital Medicine (2nd ed., pp. 941-953). McGraw Hill Education. 
